\title{
Sensoriamento Remoto HidRoacústico no Mapeamento DE MaCRófitas Aquáticas SubMersas ${ }^{1}$
}

\author{
Hydro-Acoustic Remote Sensing in Submerged Aquatic Macrophyte Mapping
}

ROTTA, L.H.S. ${ }^{2}$, IMAI, N.N. ${ }^{2}$, BATISTA, L.F.A. ${ }^{2,3}$, BOSCHI, L.S. ${ }^{2}$, GALO, M.L.B.T. ${ }^{2}$ e VELINI, E.D. ${ }^{4}$

\begin{abstract}
RESUMO - Macrófitas são importantes produtoras primárias do ecossistema aquático, e o desequilibrio do ambiente pode ocasionar seu crescimento acelerado. Portanto, levantamentos de dados relacionados a macrófitas submersas são importantes para contribuir na gestão de corpos de água. Contudo, a amostragem dessa vegetação requer um enorme esforço físico. Nesse sentido, a técnica hidroacústica é apropriada para o estudo de macrófitas submersas. Assim, os objetivos deste trabalho foram avaliar os tipos de dados gerados pelo ecobatimetro e analisar como esses dados caracterizam a vegetação. Utilizou-se o ecobatímetro BioSonics DT-X acoplado a um GPS. A área de estudo é um trecho do Rio Uberaba, MG. A amostragem foi feita por meio de transectos, navegando de uma margem à outra. Depois de processar os dados, obteve-se informação a respeito de ocorrência de macrófitas submersas, profundidade, altura média das plantas, porcentagem da cobertura vegetal e posição. A partir desse conjunto de dados, foi possivel extrair outras duas métricas: biovolume e altura efetiva do dossel. Os dados foram importados de um Sistema de Informação Geográfica e geraram-se mapas ilustrativos das variáveis estudadas. Além disso, quatro perfis foram selecionados para analisar a diferença entre as grandezas de representação de macrófitas. O ecobatímetro mostrou-se uma ferramenta eficaz no mapeamento de macrófitas submersas. Cada uma das medidas - altura do dossel, ECH ou biovolume - caracteriza de forma diferente a vegetação submersa. Dessa forma, a escolha do tipo de representação depende da aplicação desejada.
\end{abstract}

Palavras-chave: Egeria densa, Egeria najas, ecobatímetro, geoprocessamento, altura efetiva do dossel, biovolume.

\begin{abstract}
Macrophytes are important aquatic ecosystem primary producers. Environmental imbalance may cause their rapid growth. Thus, collecting data related to submerged macrophytes can favor water body management. Since a great physical effort is required to sample this vegetation, a hydro-acoustic technique has been appropriate to study submerged macrophytes. Evaluating data types generated by the echo-sounder and analyzing how it characterizes vegetation were established as objectives. A BioSonics DT-X echo-sounder linked to a GPS was used. The selected study area is a section of the Uberaba River, MG. The sampling consisted of transects, navigating from one side to another. Data processing provided information on the occurrence, depth, plant mean height, vegetation cover percentage, and position of the submerged macrophytes. Two other metrics - biovolume and effective canopy height-were also extracted from this data set. Imported to a Geographic Information System, collected data generated illustrative maps of the studied variables. In addition, four profiles were selected to analyze the differences in macrophyte representation methods. The echo-sounder proved to be an effective tool to develop submerged macrophyte mapping. Since the submerged vegetation is differently characterized by each measurement - canopy height, ECH or bio-volume-the choice of representation depends on the application desired.
\end{abstract}

Keywords: Egeria densa, Egeria najas, echo-sounder, geo-processing, effective canopy height, bio-volume.

1 Recebido para publicação em 9.12.2011 e aprovado em 15.1.2012.

2 Faculdade de Ciências e Tecnologia, Universidade Estadual Paulista - FCT/UNESP, Caixa Postal 305, $19060-900$ Presidente Prudente-SP, Brasil, <luizhrotta@yahoo.com.br>, <nnimai@fct.unesp.br>, <ligia@utfpr.edu.br>, <leticiasabo@yahoo.com.br>, <mlourdes@fct.unesp.br>; ${ }^{3}$ Universidade Tecnológica Federal do Paraná - UTFPR, 86036-370 Londrina-PR, Brasil, $<$ ligia@utfpr.edu.br>; ${ }^{4}$ Faculdade de Ciências Agronômicas, Universidade Estadual Paulista - FCA/UNESP, Caixa Postal 237, 18603-970 Botucatu-SP, Brasil, <velini@fca.unesp.br>.

Planta Daninha, Viçosa-MG, v. 30, n. 2, p. 229-239, 2012 


\section{INTRODUÇÃO}

Tradicionalmente, os estudos de taxa de produtividade primária relacionados a macrófitas submersas são realizados sob condições controladas, em laboratório, ou pela avaliação da biomassa, in situ, normalmente pelo método do quadro (Michelan et al., 2010), o qual é seguido de procedimentos de secagem e pesagem.

Especificamente no que se refere a macrófitas submersas, o método do quadro requer intenso esforço físico para amostragem, além das questões relacionadas ao transporte do material retirado. Ressalta-se ainda que, por ser um método destrutivo, dificulta a realização de estudos temporais, uma vez que exige amostragens em locais diferentes em cada período (Silva et al., 2010).

Técnicas alternativas, como a utilização de sensoriamento remoto óptico, podem ser aplicadas (Galo et al., 2002; Rotta et al., 2011). Entretanto, apresentam certas restrições, devido à atenuação da radiação eletromagnética na coluna d'água, limitando a identificação de vegetação submersa até uma determinada profundidade (Hestir et al., 2008).

Quando comparadas com ondas eletromagnéticas, as ondas sonoras ultrapassam a coluna de água e se propagam de maneira muito mais eficiente em meios aquáticos, sendo, assim, melhor alternativa para obter informações sobre alvos submersos. Segundo Lurton (2002), os sistemas acústicos utilizados para detectar e/ou localizar alvos ou obstáculos são chamados de SONAR. O termo SONAR (SOund, NAvigation and Ranging - Navegação e Medição de Distância pelo Som) foi utilizado primeiramente na Segunda Guerra Mundial pelos Estados Unidos (Jensen, 2009). As ondas sonoras geradas viajam pelo corpo d'água até atingirem o alvo e retornam, por meio do eco, ao sistema (Urick, 1975).

O ecobatímetro gera dados georreferenciados da altura dos dosséis e da densidade, dada pela proporção de pontos classificados como vegetação em cada ciclo, ou conjunto de pulsos. Essas duas medidas podem ser combinadas de diferentes formas para representar a ocupação das macrófitas submersas. De modo geral, possibilitam avaliar a ocupação da vegetação em termos de área e também em uma terceira dimensão, que representa a altura dos dosséis.

Dessa forma, a técnica hidroacústica mostra-se interessante para mapeamento da área e geometria de ocupação por macrófitas submersas. Os objetivos deste trabalho foram avaliar os tipos de dados gerados pelo ecobatímetro e analisar como esses dados caracterizam a vegetação.

\section{MATERIAL E MÉTODOS}

O estudo foi realizado em um trecho do rio Uberaba, afluente do rio Grande, delimitado aproximadamente pelas coordenadas $48^{\circ} 32^{\prime} 19^{\prime \prime} \mathrm{W}, 20^{\circ} 01^{\prime} 44^{\prime \prime} \mathrm{S}$ e $48^{\circ} 31^{\prime} 47^{\prime \prime} \mathrm{W}$, $20^{\circ} 01^{\prime} 09^{\prime \prime S}$ (Figura 1). A área está localizada no reservatório de Porto Colômbia. Essa região, de aproximadamente $300.000 \mathrm{~m}^{2}$, foi escolhida por ser uma área com presença de macrófitas submersas e de fácil navegação.

Para coleta dos dados utilizou-se o sonar digital científico BioSonics DT-X (ecobatímetro). Esse sistema pode ser configurado para diferentes aplicações, tanto em ambientes marinhos como em ambientes de água doce. Algumas das aplicações são: batimetria, monitoramento de habitat, distribuição de plantas e sedimentos, entre outros (Biosonics, 2011).

Os componentes que formam o sistema ecobatímetro DT-X são: unidade de superficie - contém processador dedicado à operação do ecobatímetro, onde é gerado o sinal e controlada a operação do transdutor; transdutor ligado à unidade de superficie por meio de cabo de sinal digital, converte o sinal elétrico emitido pela unidade de superficie em pulso acústico e transforma o eco do pulso em sinal elétrico; dispositivo de comunicação externa (notebook) interligado via interface ethernet - utilizado para carregar parâmetros operacionais do sistema, além de exibir e armazenar os dados recebidos do ecobatímetro; e GPS - ligado à unidade de superficie, fornece a referência geográfica para os dados acústicos (Biosonics, 2004).

Os dados foram adquiridos em uma campanha de campo realizada no dia 27 de setembro de 2009. O receptor GPS utilizado no 


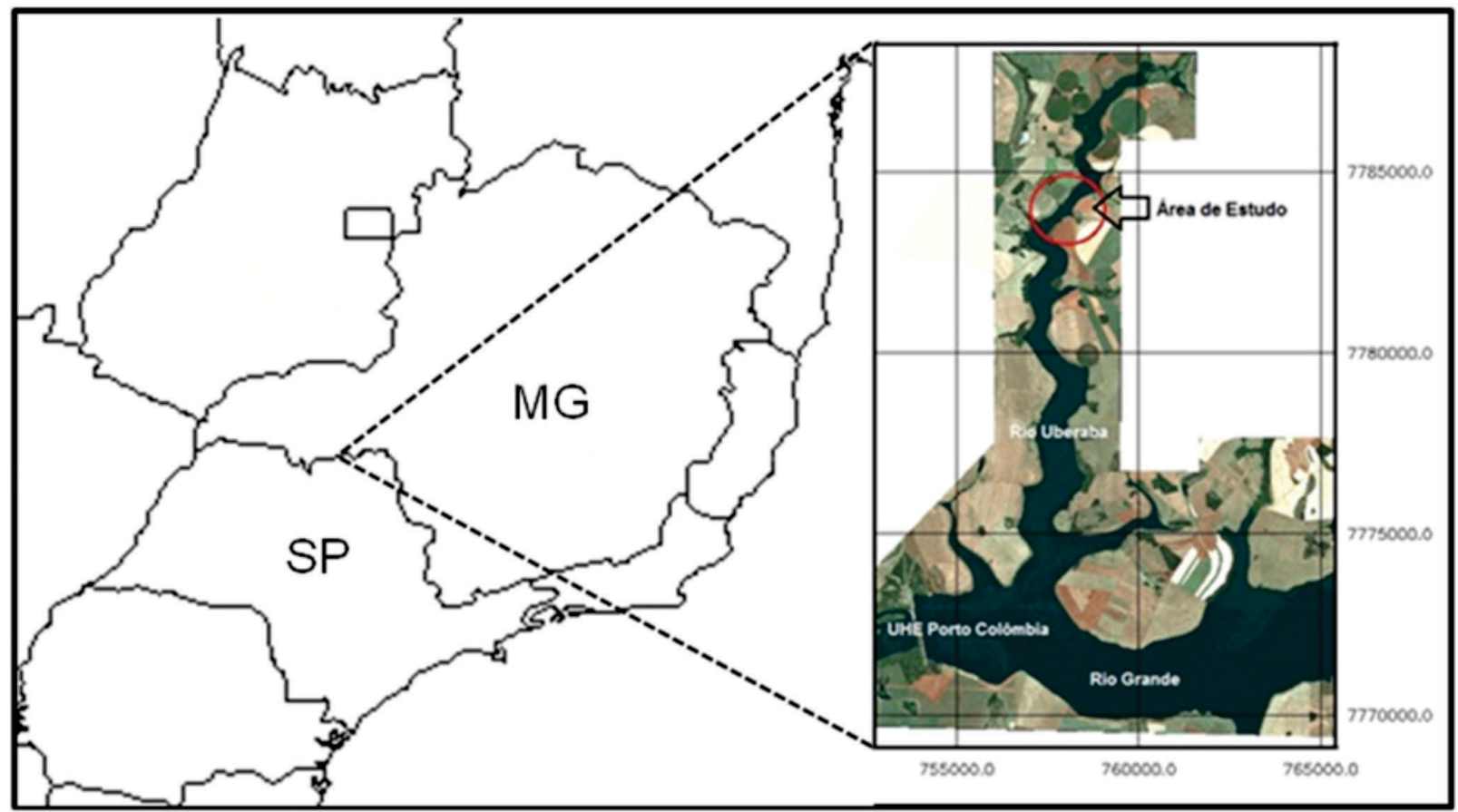

Figura 1 - Área de estudo.

sistema foi o Garmin e Trex Vista (GPS de navegação), cuja incerteza de posicionamento foi de aproximadamente $7 \mathrm{~m}$. O sistema de referência adotado no trabalho foi o WGS-84. Os dados foram obtidos no sistema de coordenadas geográficas (latitude, longitude); para que a codificação dos dados, ou seja, as coordenadas fossem integradas ao sistema de navegação do ecobatímetro, adotou-se o padrão NMEA.

A amostragem foi feita por transectos de uma margem à outra. Nesse contexto, a definição de transecto denota os trechos paralelos do percurso realizado pelo barco durante o mapeamento. Para auxiliar na orientação dos transectos, utilizou-se outro GPS de navegação. Além disso, este também foi utilizado com o intuito de controlar a velocidade do barco, a qual foi mantida em aproximadamente $7 \mathrm{~km} \mathrm{~h}^{-1}$, conforme recomendação do fabricante do ecobatímetro.

Para viabilizar o levantamento ecobatimétrico, foi especificado um suporte que permitisse a integração do ecobatímetro com o GPS e possibilitasse sua instalação em um barco de fácil operação. O suporte para o ecobatímetro foi construído com barras de ferro

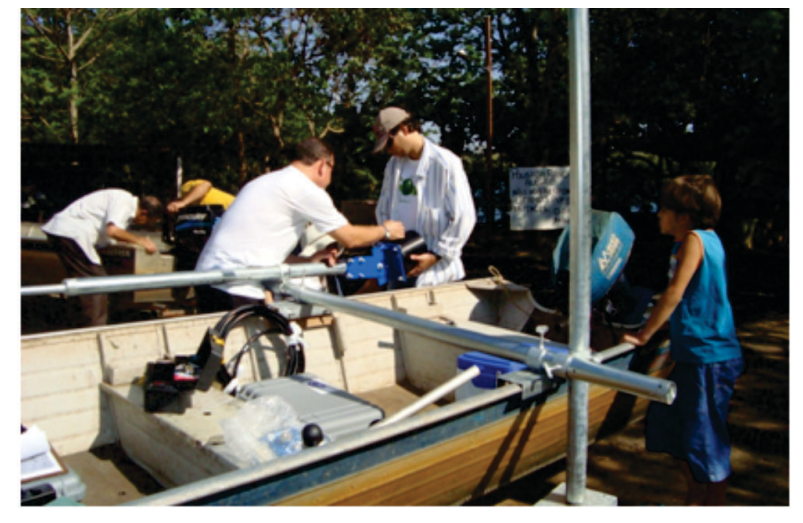

Figura 2 - Instalação do equipamento hidroacústico no barco.

e baseado no protótipo de Coelho (2008), o qual é de fácil construção, transporte e montagem, não ocupando espaço no barco (Figura 2).

O transdutor do ecobatímetro foi posicionado verticalmente a uma profundidade de $0,5 \mathrm{~m}$ em uma das laterais do barco, e na extremidade da mesma haste foi colocada a antena do GPS. Por meio do notebook, os dados obtidos pelo ecobatímetro são visualizados em tempo real e armazenados em arquivos individuais para cada transecto. $\mathrm{O}$ sistema 
é controlado a partir do software Visual Acquisition. Esse software mostra um ecograma, que descreve a profundidade do relevo submerso em tempo real e a presença ou ausência de macrófitas aquáticas submersas (Figura 3).

O software Visual Acquisition foi configurado para a detecção de macrófitas aquáticas submersas. Para isso, utilizaram-se valores recomendados por Sabol (2003) (Tabela 1).

Depois de armazenados, os dados foram analisados com o software Visual Analyser. Por meio desse aplicativo, foi possivel indicar a profundidade máxima de ocorrência de macrófitas aquáticas submersas de cada arquivo armazenado. Essa informação foi utilizada no software EcoSAV.

$\mathrm{O}$ software EcoSAV, juntamente com o ecobatímetro DT-X, tem sido usado pelos pesquisadores de vegetação aquática submersa para estimar e localizar as numerosas espécies de vegetação aquática submersa em ambientes tanto maritimos quanto lacustres. É um software de pós-processamento capaz de adquirir informações a respeito de vegetação aquática submersa (presença ou ausência), profundidade, altura média das plantas, porcentagem da cobertura vegetal, posição, dia e horário (Biosonics, 2008).

A Figura 4 mostra uma representação gráfica de como o EcoSAV apresenta os dados para cada pulso do ciclo e, em seguida, como calcula os dados de todo o ciclo. Dois ciclos são apresentados como exemplo.

Cada feixe acústico mostrado na Figura 4 corresponde a um pulso único, e o conjunto desses 10 pulsos representa um ciclo. As séries de círculos (10 pulsos) apresentados em amarelo e marrom representam a área amostrada pelo ecobatímetro e as cores indicam como os pulsos foram classificados: com presença (amarelo) ou ausência de plantas (marrom).

Os dados de porcentagem de cobertura vegetal, altura média e posição fornecidos são

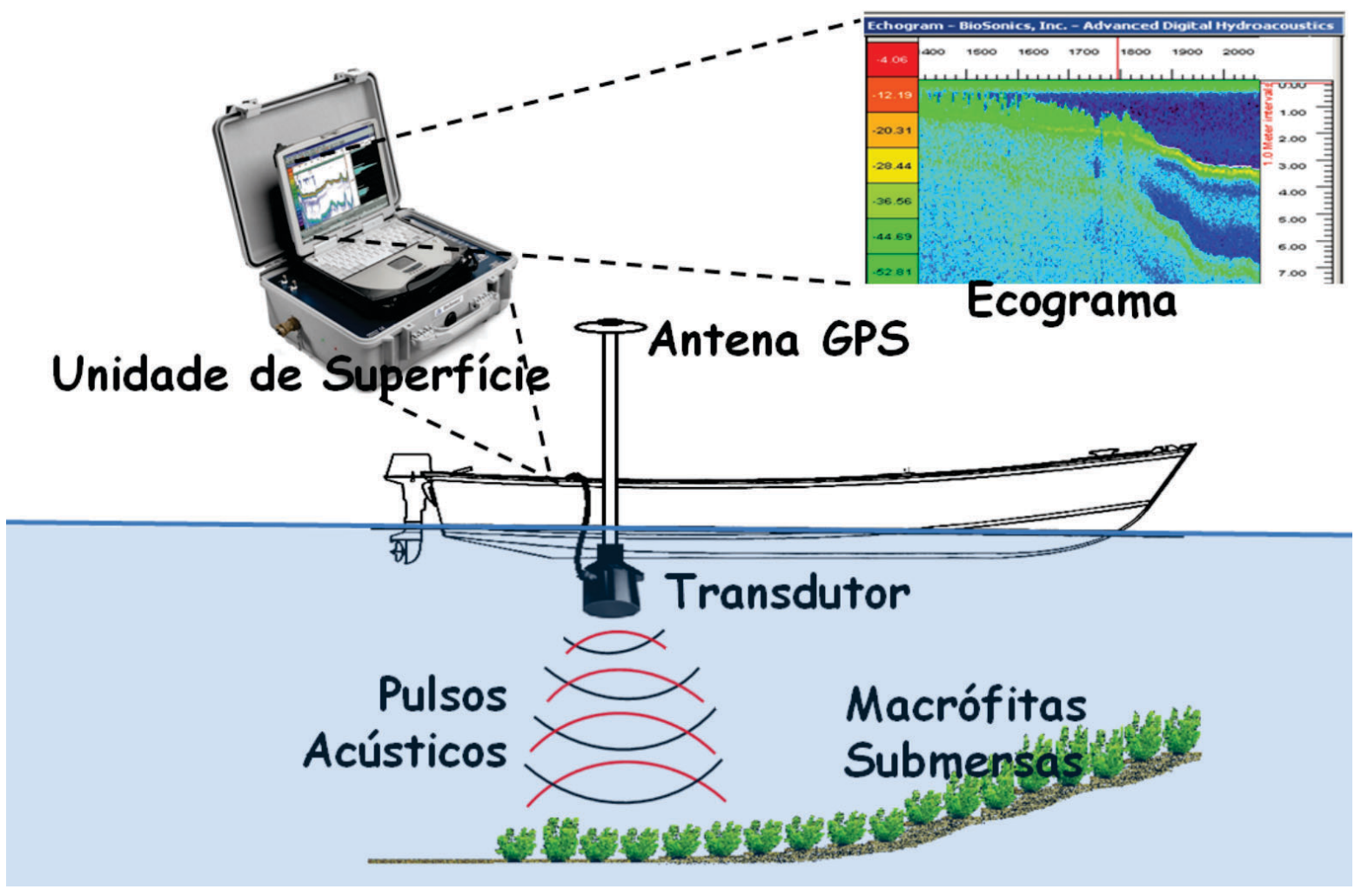

Figura 3 - Esquema de aquisição de dados com o ecobatímetro. 
Tabela 1 - Configuração do ecobatímetro para detecção de macrófitas submersas

\begin{tabular}{|l|l|l|}
\hline \multicolumn{2}{|l|}{ Parâmetro } & \multicolumn{1}{c|}{ Valor e configurações } \\
\hline Receptor & Modo de operação & Feixe simples \\
\hline \multirow{4}{*}{ Parâmetros de coleta de dados } & Profundidade mínima & $0 \mathrm{~m}$ \\
\cline { 2 - 3 } & Profundidade máxima & $50 \%$ maior que a máxima profundidade \\
\cline { 2 - 3 } & Valor limiar & $-130 \mathrm{db}$ \\
\cline { 2 - 3 } Parâmetros ambientais & Modo limiar & Quadrático \\
\hline \multirow{2}{*}{$\begin{array}{l}\text { Opções de armazenamento de } \\
\text { dados }\end{array}$} & $\begin{array}{l}\text { Temperatura } \\
\text { Profundidade } \\
\text { pH } \\
\text { Salinidade }\end{array}$ & $\begin{array}{l}\text { Valores importantes para calcular a } \\
\text { velocidade do som e absorção. O uso de } \\
\text { valores exatos para águas rasas não é crítico. }\end{array}$ \\
\hline Controle do pulso & Criação automática do arquivo de dados & Por tempo, 30 minutos \\
\hline & Nome do arquivo & $\begin{array}{l}\text { Nome é gerado com o horário do início de } \\
\text { cada coleta (a cada 30 minutos) }\end{array}$ \\
\hline Modo acústico & Taxa de emissão & 5 pps (pings por segundo) \\
\hline
\end{tabular}

Fonte: Sabol (2003).

gerados a partir dos cálculos apresentados na Figura 4. A Tabela 2 (A) ilustra um exemplo dos dados de saída do software EcoSAV.

A partir das medidas de altura do dossel, cobertura e profundidade, foram extraídas outras duas métricas, que caracterizam a vegetação: biovolume e altura efetiva do dossel.

O cálculo de biovolume é dado pela altura da vegetação relativa à profundidade, expresso em percentual, como colocado na equação 1 (Valley et al., 2005). Essa medida é relativa e representa a proporção vertical da coluna d’água colonizada pela vegetação.

$$
\text { Biovolume }=\frac{\text { altura vegetação }}{\text { profundidade }} * \text { cobertura }
$$

Sabol et al. (2009) propuseram a combinação da medida de altura do dossel ponderada pela cobertura, a qual determina a densidade do dossel no ciclo dos dez pulsos. A medida proposta foi denominada de Effective Canopy Height (ECH). Essa grandeza é importante para corrigir casos em que os valores poderiam ser superestimados se usada apenas a medida de altura gerada pelo ecobatimetro, quando poucos dosséis forem detectados em uma área de baixa cobertura. Essa nova métrica é dada pela equação 2 .

$$
E C H=\frac{\text { altura vegetação } * \text { cobertura }}{100}
$$

(eq. 2)

A Tabela 2 (B) exemplifica os dados resultantes da aplicação das equações 1 e 2 .

As tabelas contendo altura da vegetação, biovolume, ECH e profundidade foram convertidas em formato compativel para serem importadas em um ambiente SIG; no caso, foi utilizado o software SPRING (Figura 5) (Câmara et al., 1996).

Cada linha da Tabela 2 corresponde, na representação espacial, a um vetor do tipo ponto com atributos. Devido às características do software, cada atributo (altura, biovolume, $\mathrm{ECH}$ e profundidade) é representado em um Plano de Informação (PI) distinto, como pode ser observado na Figura 5.

Os modelos digitais de terreno mais utilizados na prática são: os modelos de grade regular retangular e os de grade irregular triangular. O processo de geração de um modelo de grade compreende a construção de 


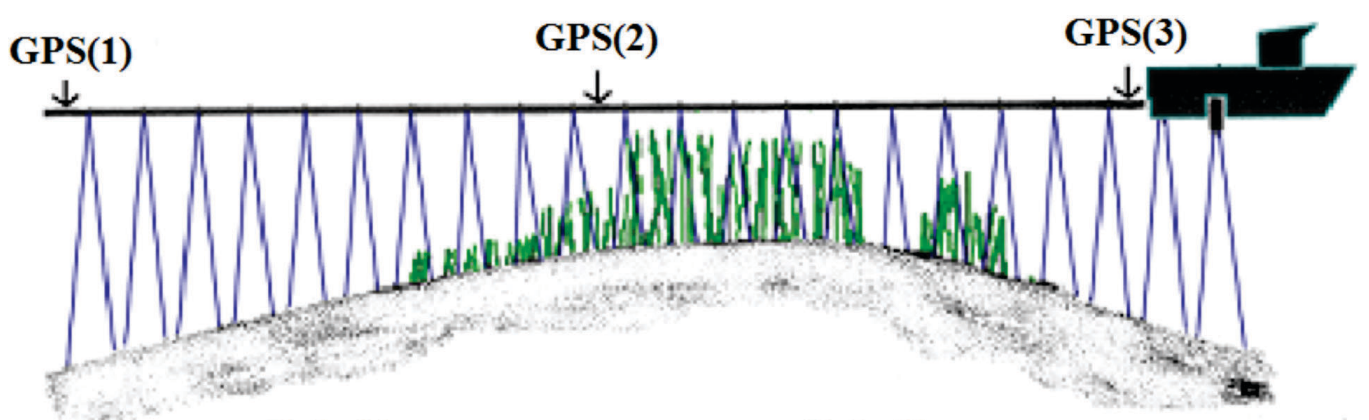

Ciclo \#1

Ciclo \#2

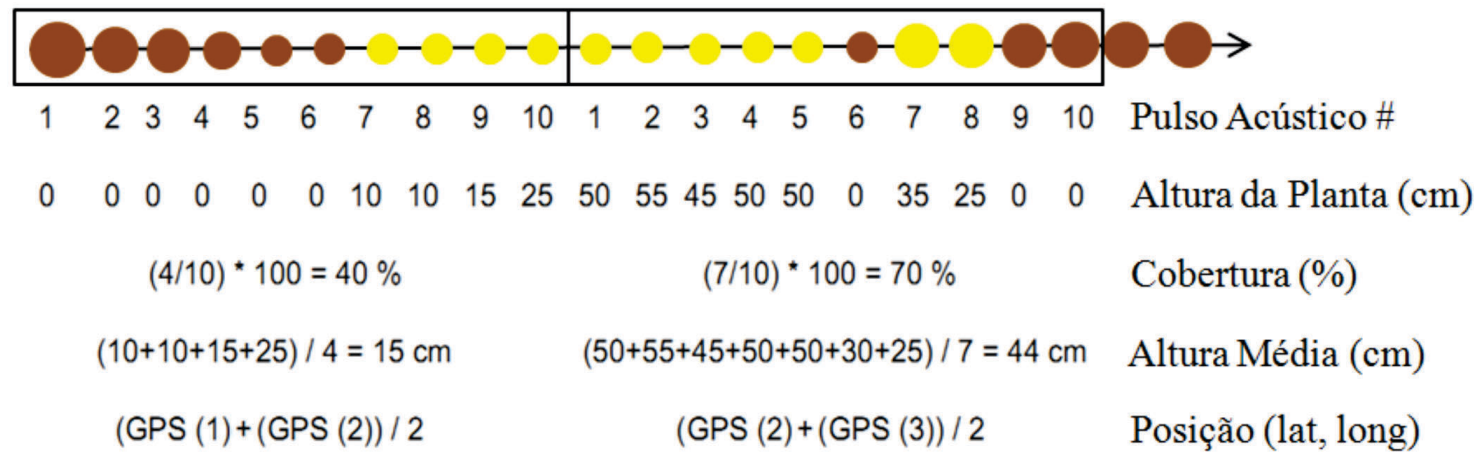

Fonte: Adaptado de BIOSONICS (2008)

Figura 4 - Princípios dos algoritmos de caracterização de plantas no EcoSAV.

Tabela 2 - Dados do ecobatímetro após processamento no software EcoSAV para obtenção de informações referentes à vegetação aquática submersa (A); e dados de biovolume e ECH adquiridos por meio da aplicação das equações 1 e 2 nos dados obtidos com o $\operatorname{EcoSAV}(\mathrm{B})$

\begin{tabular}{|c|c|c|c|c|c|c|}
\hline \multicolumn{4}{|c|}{ (A) Dados de Saída: EcoSAV } & \multicolumn{2}{c|}{ (B) Dados: Equações 1 e 2 } \\
\hline $\begin{array}{c}\mathrm{E} \\
(\mathrm{m})\end{array}$ & $\begin{array}{c}\mathrm{N} \\
(\mathrm{m})\end{array}$ & $\begin{array}{c}\text { Profundidade } \\
(\mathrm{m})\end{array}$ & $\begin{array}{c}\text { Altura média } \\
(\mathrm{m})\end{array}$ & $\begin{array}{c}\text { Cobertura } \\
(\%)\end{array}$ & $\begin{array}{c}\text { Biovolume } \\
(\%)\end{array}$ & $\begin{array}{c}\text { ECH } \\
(\mathrm{m})\end{array}$ \\
\hline 757836 & 7783654 & 1,66 & 0,79 & 100 & 47,59 & 0,79 \\
\hline 757822 & 7783653 & 2,40 & 0,43 & 80 & 14,33 & 0,34 \\
\hline 757819 & 7783653 & 2,70 & 0,15 & 100 & 5,56 & 0,15 \\
\hline 757803 & 7783654 & 3,58 & 0,19 & 90 & 4,78 & 0,17 \\
\hline 757796 & 7783655 & 4,07 & 0,28 & 100 & 6,88 & 0,28 \\
\hline 757780 & 7783658 & 5,22 & 0,29 & 70 & 3,89 & 0,20 \\
\hline 757777 & 7783659 & 5,69 & 0,00 & 0 & 0,00 & 0,00 \\
\hline$\vdots$ & $\vdots$ & $\vdots$ & $\vdots$ & $\vdots$ & $\vdots$ & $\vdots$ \\
\hline
\end{tabular}

uma malha, regular ou irregular, e a definição de funções interpolantes locais. Essas funções são definidas para cada elemento da malha (Felgueiras, 2001).

No presente trabalho foi utilizado o modelo de grade regular com interpolação por média ponderada. Nesse caso, o valor dos nós da grade é definido pela média ponderada, com base no inverso da distância euclidiana, dos valores de cota das amostras vizinhas. Assim, quanto mais distante uma amostra se encontra do ponto da grade, menor deve ser a sua influência. 


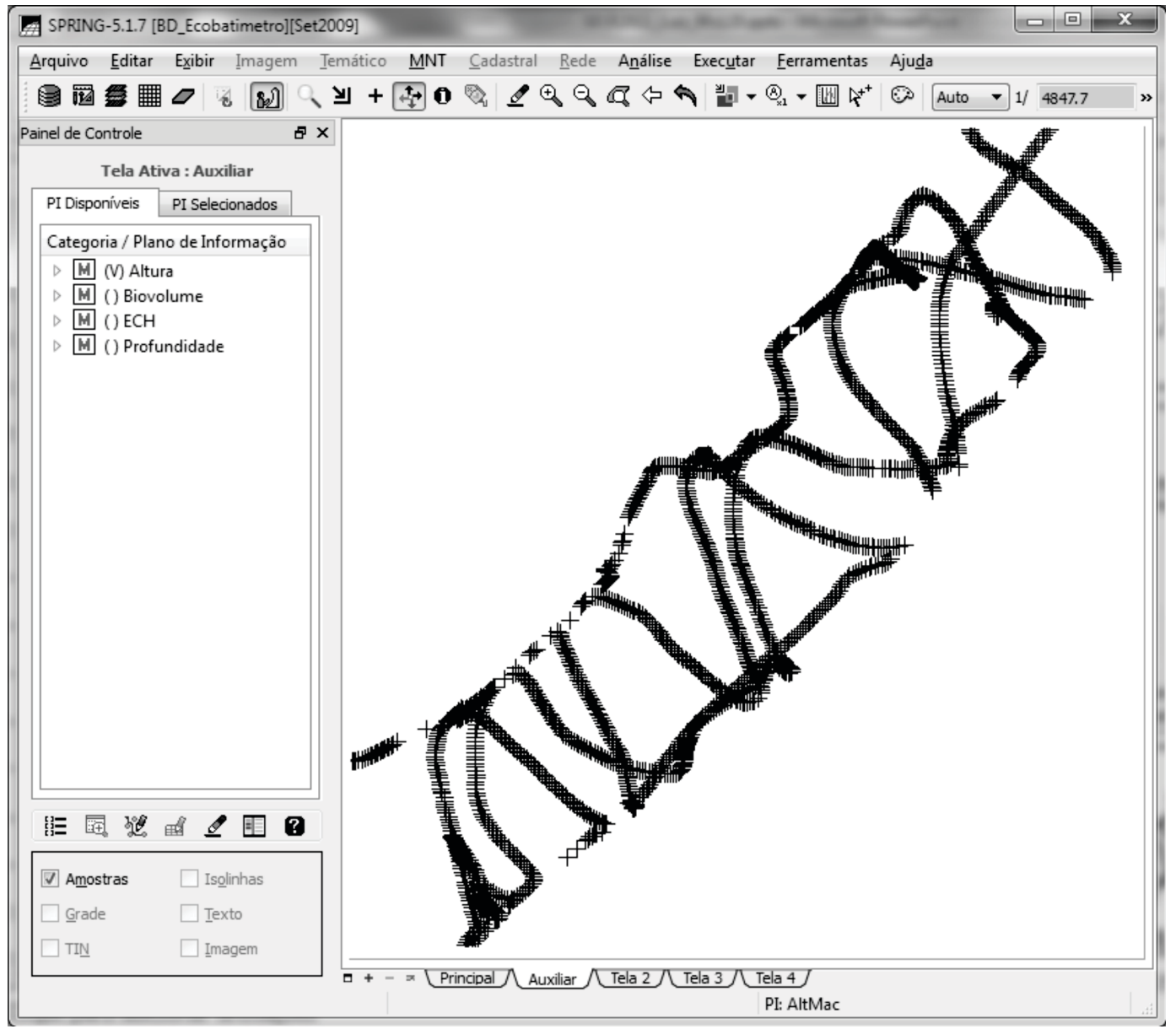

Figura 5 - Distribuição espacial da amostragem com o ecobatímetro: software SPRING.

Para gerar mapas temáticos das variáveis estudadas, aplicou-se um fatiamento nas grades retangulares interpoladas, produzindo classes conforme a grandeza adotada.

Finalmente, para analisar a diferença entre os métodos de representação de macrófitas submersas, foram selecionados, aleatoriamente, quatro perfis ao longo dos transectos.

\section{RESULTADOS E DISCUSSÃO}

As Figuras 6, 7 e 8 mostram a altura, ECH e biovolume da vegetação aquática submersa, respectivamente. Vale ressaltar que as espécies de macrófitas submersas presentes na área de estudo são Egeria densa e Egeria najas. Essas figuras mostram os principais tipos de mapas que podem ser obtidos com o ecobatimetro (BioSonics DT-X) no estudo da vegetação aquática submersa.
A região estudada está altamente colonizada por macrófitas submersas, ou seja, a densidade (cobertura) de vegetação encontrada foi quase sempre próxima de $100 \%$. Com isso, os valores para ECH (Equação 2) ficaram sempre próximos dos próprios valores de altura. Dessa forma, como pode ser observado nas Figuras 6 e 7, os mapas de altura e de ECH foram bastante similares.

A Figura 8 está relacionada com a proporção de volume ocupado pela planta imersa. Assim, o mapa de biovolume é distinto dos demais.

A Figura 9 (A, B, C, D) mostra quatro perfis transversais escolhidos aleatoriamente da amostra para analisar a diferença entre as representações de macrófitas submersas obtidas com o ecobatimetro. 


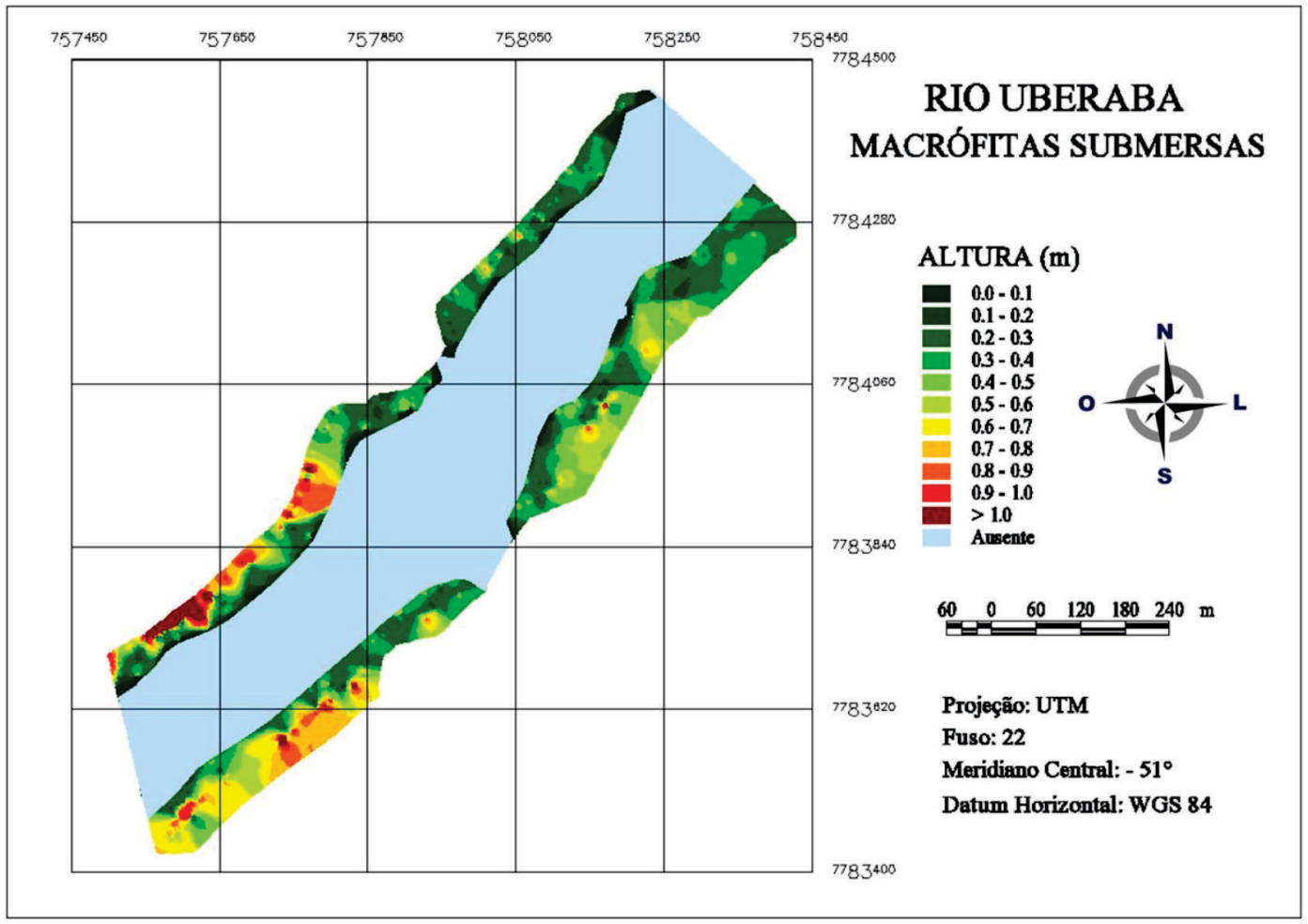

Figura 6 - Altura das macrófitas submersas.

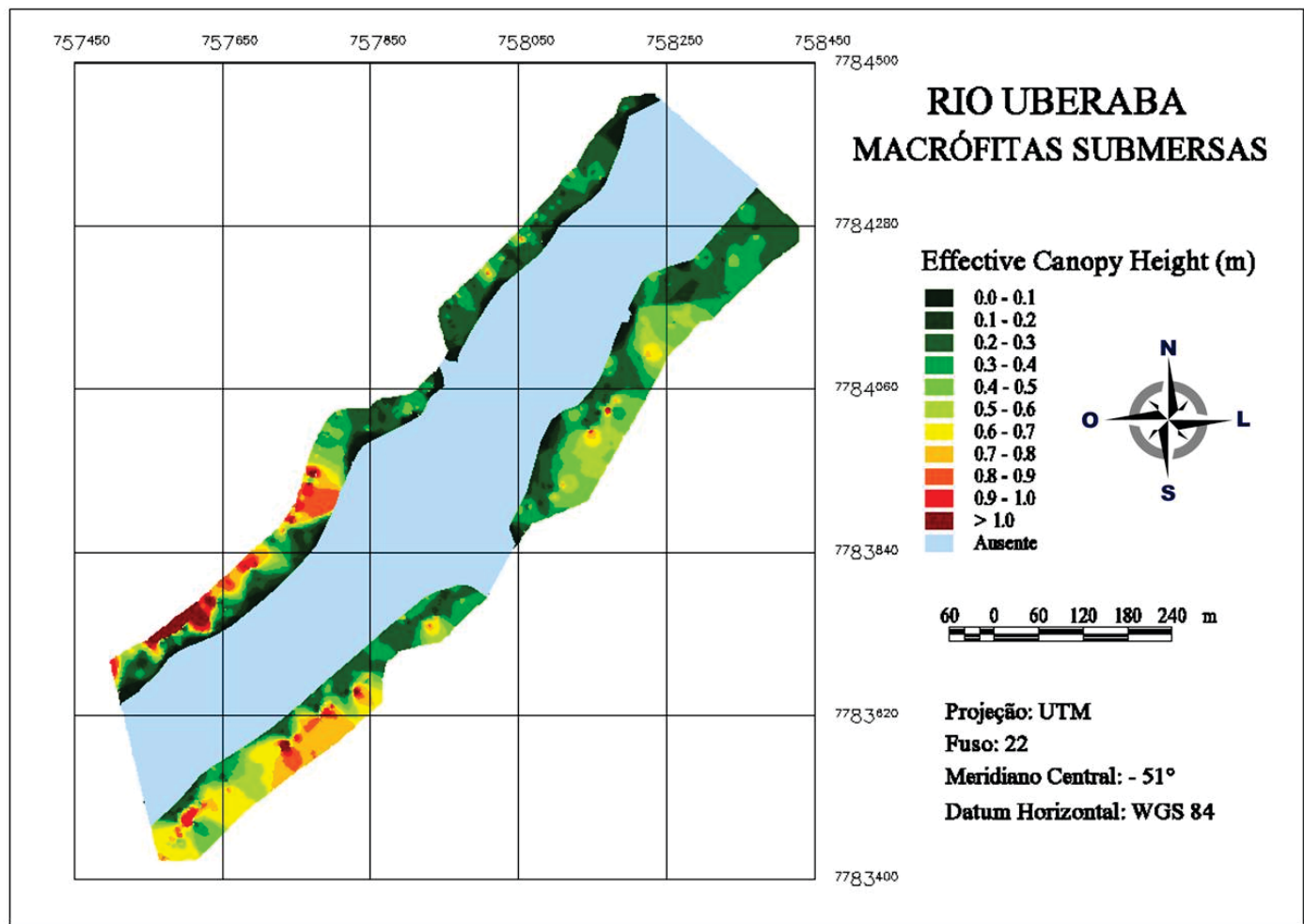

Figura 7 - Effective Canopy Height das macrófitas submersas. 


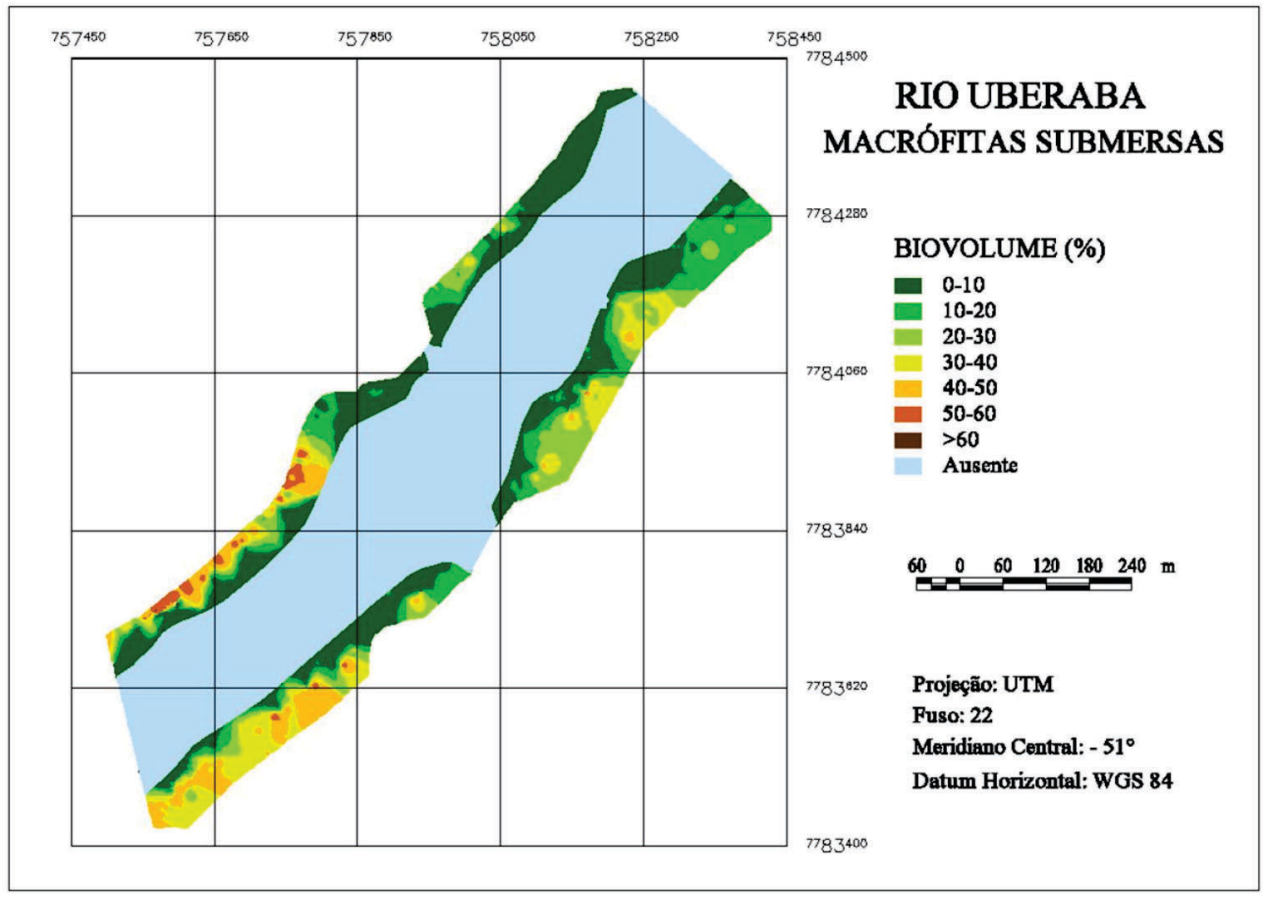

Figura 8 - Biovolume das macrófitas submersas.

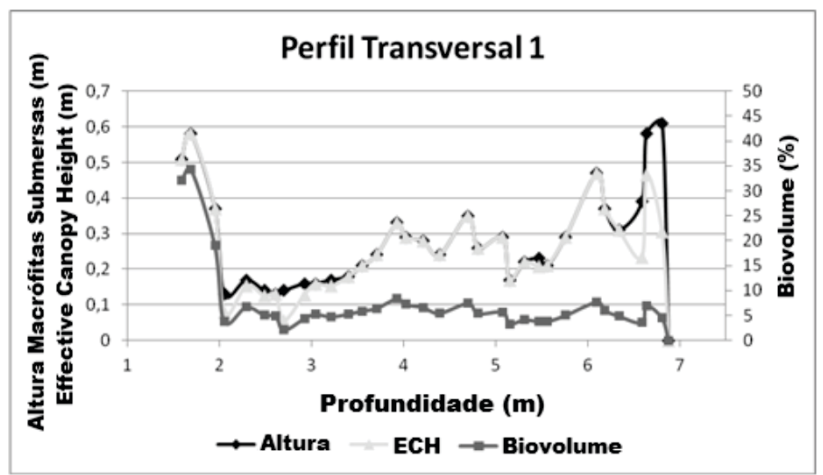

(A)

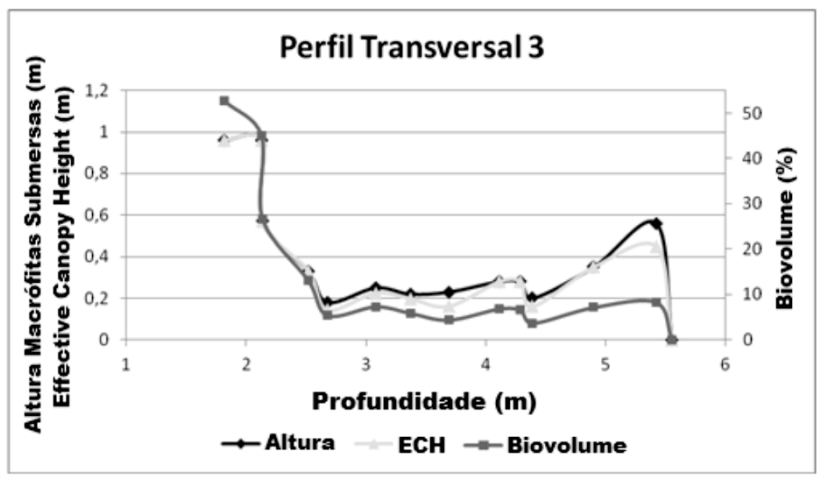

(C)

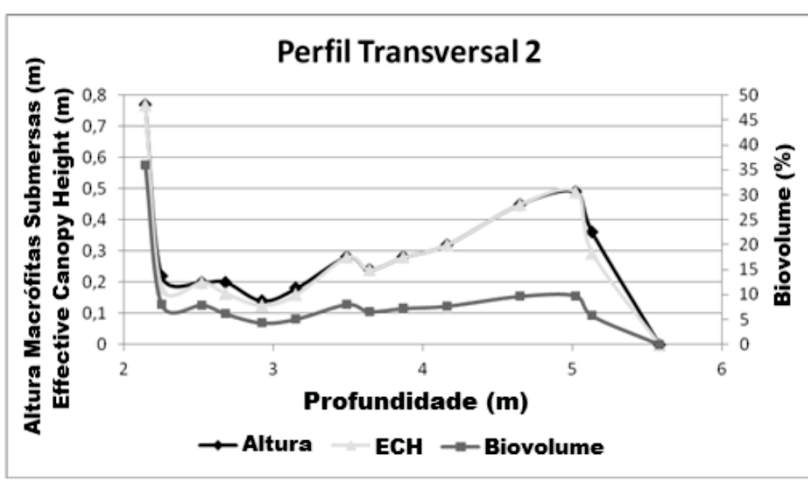

(B)

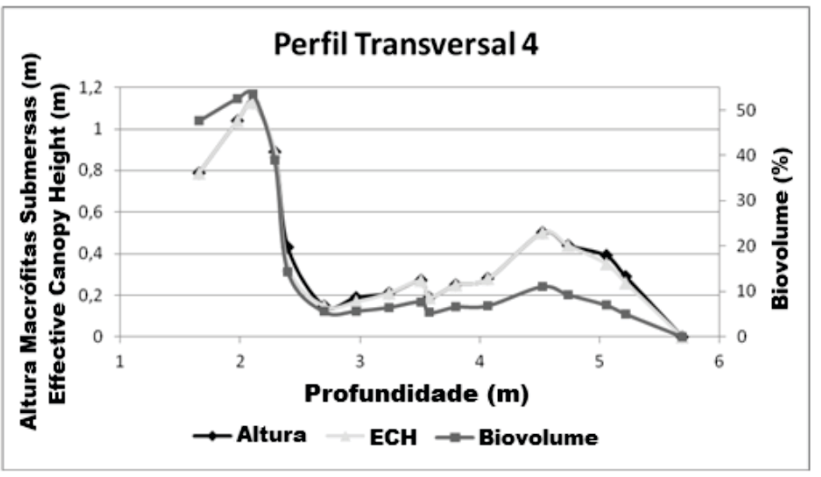

(D)

Figura 9 - Perfis transversais em quatro transectos, representando a altura, o ECH e o biovolume das macrófitas imersas. 
Os perfis de altura e ECH (Figura 9) mostraram-se bastante similares, conforme já observado nos mapas das Figuras 6 e 7. Esse comportamento é justificado pela alta concentração de macrófitas submersas nessa região.

Com relação ao biovolume, observa-se que em regiões próximas às margens, onde a vegetação submersa ocupa quase toda a coluna da água, a magnitude dessas curvas é bastante parecida com a das demais. Já em regiões mais profundas, as feições dos perfis são similares, mas com diferentes magnitudes. Além disso, observa-se que o perfil do biovolume é mais suavizado que os outros, pois se trata de uma variável dependente da profundidade, e isso faz com que as feições sejam atenuadas.

Cada uma das medidas (altura do dossel, $\mathrm{ECH}$ ou biovolume) caracteriza de forma diferente a vegetação submersa. Biovolume é uma medida relativa, que reflete a proporção da profundidade ocupada pela vegetação. Já altura e ECH são medidas absolutas, as quais fornecem dados semelhantes quando a área está altamente infestada. Em caso de vegetação mais esparsa, a opção por ECH é a melhor, a fim de não superestimar os dados. Quanto a escolher entre a medida absoluta ou relativa, isso depende da aplicação. O biovolume pode caracterizar melhor o grau de infestação, pois dá ideia do quanto a ocupação do corpo d'água está próxima do máximo. No caso de avaliação de crescimento, a medida absoluta apresenta-se como melhor opção.

Com relação ao levantamento de dados georreferenciados para mapeamento de macrófitas submersas, o ecobatímetro mostrouse uma ferramenta eficaz. Assim, o uso de equipamentos hidroacústicos para detectar a vegetação aquática submersa pode contribuir na gestão de corpos de água, permitindo aprimorar o conhecimento sobre o ecossistema local e, com isso, se necessário, elaborar uma estratégia de ação para conter a proliferação dessa vegetação.

\section{LITERATURA CITADA}

BIOSONICS. User Guide: EcoSAV ${ }^{\mathrm{TM}} 1$. BioSonics Inc: Seattle, 2008. 48 p.

BIOSONICS. User Guide: Visual Acquisition ${ }^{\mathrm{TM}}$ 5.0. Biosonics Inc: Seattle, 2004. 60 p.

Planta Daninha, Viçosa-MG, v. 30, n. 2, p. 229-239, 2012
BIOSONICS. Web Site. Disponível em:

<www.biosonicsinc.com>. Acesso em: 22 set. 2011.

CÂMARA, G; SOUZA, R. C. M.; FREITAS, U. M.; GARRIDO, J. SPRING: Integrating remote sensing and GIS by object-oriented data modelling. Computers \& Graphics, v. 20 , n. 3 , p. $395-403,1996$

COELHO, R. M. P. Uma nova ferramenta na gestão de reservatórios em Minas Gerais: Avaliação - em tempo real - da disponibilidade de recursos pesqueiros através da utilização de técnicas hidroacústicas. Belo Horizonte: Relatório final de atividades - FAPEMIG, 2008. 85 p.

FELGUEIRAS, C. A. Modelagem numérica de terreno. In: CÂMARA, G.; DAVIS, C. MONTEIRO, A. M. V. Introdução à ciência da geoinformação. São José dos Campos: INPE, 2001. 345 p.

GALO, M. L. B. T.; VELINI, E. D.; TRINDADE M. L. B.; SANTOS, S. C. A. Uso do sensoriamento remoto orbital no monitoramento da dispersão de macrófitas nos reservatórios do Complexo Tietê. Planta Daninha, v. 20, p. 7-20, 2002. Edição Especial.

HESTIR, E. L. KHANNA, S. ANDREW, M. E. Remote sensing of environment identification of invasive vegetation using hyperspectral remote sensing in the California Delta ecosystem. Remote Sensing of Environment, v. 112, n. 11, p. $4034-4047,2008$

JENSEN, J. R. Sensoriamento remoto do ambiente: uma perspectiva em recursos terrestres. Tradução: EPIPHANIO, J. C. (coordenador); FORMAGGIO, A. R.; SANTOS, A. R.; RUDORFF, B. F. T.; ALMEIDA, C. M.; GALVÃO, L. S. São José dos Campos, SP: Parêntese, 2009. 672 p.

LURTON, X. An introduction to underwater acoustics: principles and applications. London; Berlin; Heidelberg; New York; Barcelona; Hong Kong; Milan; Paris; Santa Clara; Singapore; Tokyo: Springer; Chichester, UK: Praxis Publ., 2002. 347 p.

MICHELAN, T. S.; THOMAZ, S. M.; MORMUL, R. P.; CARVALHO, P. Effects of an exotic invasive macrophyte (tropical signalgrass) on native plant community composition, species richness and functional diversity. Freshwater Biology, v. 55, n. 6, p. 1315-1326, 2010.

ROTTA, L. H. S. IMAI, N. N. BOSCHI, L. S.; BATISTA, L. F.A. Detecção de macrófitas submersas por meio de imagem QuickBird - estudo de caso: Usina hidrelétrica de Porto Colômbia - MG/SP. In: SIMPÓSIO BRASILEIRO DE SENSORIAMENTO REMOTO - SBSR, 15., Curitiba. Anais... São José dos Campos: MCT/INPE, p. 4460-4467, 2011.

SABOL, B. M. Operating instructions manual for the acoustic - based submersed aquatic plant mapping system. U.S. Army Corps of Engineers. 2003. 17 p. 
SABOL, B. M.; KANNENBERG, J.; SKOGERBOE, J. G.

Integrating acoustic mapping into operational aquatic plant management: a case study in wisconsin. Journal of Aquatic

Plant Management, v. 47, n. 1, p. 44-52, 2009.

SILVA, T. S. F.; COSTA, M. P. F.; MELACK, J. M. Assessment of two biomass estimation methods for aquatic vegetation growing on the Amazon Floodplain. Aquatic Botany, v. 92, n. 3, p. 161-167, 2010.
URICK, R. J. Principles of underwater sound. 2.ed. New York: McGraw Hill Book Company, 1975. $384 \mathrm{p}$

VALLEY, R. D.; DRAKE, M. T.; ANDERSON, C. S. Evaluation of alternative interpolation techniques for the mapping of remotely-sensed submersed vegetation abundance. Aquatic Botany, v. 81, n. 1, p. 13-25, 2005. 